\title{
Ribozyme to TGF-B1 mRNA abrogates immunosuppressive effects of human colorectal adenocarcinoma HRT-18 cells in vitro and in vivo
}

\author{
WOLFGANG DANIEL SCHMITT ${ }^{1 *}$, ANTJE SIEGERT ${ }^{2 *}$, SANDRA STEPHANIE LACH $^{1}$, STEPHAN FUHRMANN $^{3}$, \\ ANKE KONDLA ${ }^{4}$, PER SONNE HOLM ${ }^{5}$ and STEFFEN HAUPTMANN ${ }^{2}$ \\ ${ }^{1}$ Institute of Pathology, Martin-Luther-University, 06097 Halle; ${ }^{2}$ Experimental Pharmacology and Oncology GmbH, \\ 13122 Berlin; ${ }^{3}$ Department of Hematology, Oncology, and Tumor Immunology, HELIOS Klinikum Berlin-Buch, \\ 13125 Berlin; ${ }^{4}$ Boehringer Ingelheim Pharma GmbH and Co. KG, 55216 Ingelheim am Rhein; ${ }^{5}$ Institute of \\ Experimental Oncology and Therapy Research, Technical University, 81675 Munich, Germany
}

Received March 31, 2009; Accepted June 5, 2009

DOI: 10.3892/ijo_00000405

\begin{abstract}
Transforming growth factor- $\beta 1$ (TGF- $\beta 1)$ is overexpressed in a variety of malignant epithelial tumors and was suggested to be a marker of colorectal cancer. Moreover, there is growing evidence that TGF- $\beta 1$ contributes to tumor progression by regulating tumor cell proliferation and differentiation, inducing a favorable tumor microenvironment, promoting migration and invasion, and suppressing macrophage cytotoxicity. Therefore, we stably transfected an antiTGF-\$1 hammerhead ribozyme into the human colorectal adenocarcinoma cell line HRT-18. Expression of this ribozyme resulted in significant inhibition of TGF- 31 expression on mRNA and protein level. This was associated with an enhanced tumor cell differentiation and a reduced tumor growth in vivo. The capability of tumor cells to suppress ROI production of co-cultivated human macrophages was abrogated in transfectants. Taken together, inhibition of TGF- $\beta 1$ in colorectal carcinoma cells might be an interesting therapeutic tool leading to reduced tumor cell growth and increased macrophage cytotoxicity. Thus, a gene-therapeutic approach using anti-TGF- $ß 1$ ribozyme in combination with established anti-tumor agents is of great promise.
\end{abstract}

\section{Introduction}

TGF- $\beta 1$ is one of the most important profibrogenic growth factors of the human body. This mediator is overexpressed in

Correspondence to: Dr Steffen Hauptmann, Institute of Pathology, Magdeburger Str. 14, 06097 Halle, Germany

E-mail: steffen.hauptmann@medizin.uni-halle.de

*Contributed equally

Key words: TGF- $\beta 1$, hammerhead ribozyme, colorectal carcinoma, reactive oxygen species, macrophages a variety of malignant tumors including ovarian (1), gastric (2), colorectal (3), liver (4), breast (5) and prostate carcinoma (6), malignant melanoma (7), glioblastoma (8) and pulmonary adenocarcinoma (9). Moreover, more than two thirds of the patients with colorectal carcinoma have elevated TGF- $\beta 1$ plasma levels in comparison to healthy volunteers. Plasma TGF-ß1 levels increase with higher Dukes' stage (10), and it has been shown that the TGF- $\beta 1$ level is of prognostic relevance in colorectal carcinomas, suggesting that this mediator plays a significant role in tumor progression $(11,12)$.

In fact, TGF- $\$ 1$ modulates many aspects of tumor cell behavior ranging from tumor suppression at early stages to promotion of metastasis (13). Colon carcinoma cells can switch their response to TGF- $\beta 1$ from repression of proliferation as it is the case in normal epithelial cells to growth stimulation during carcinoma progression (14). This switch seems to be associated with mutations affecting at least one component of the TGF- $\beta$ signaling pathway (15) or with an activated JNK-pathway (16). Additionally to this growth promoting role we have previously shown that TGF- $\beta 1$ is one of the key regulators of extracellular matrix composition (17) and therefore involved in formation of desmoplastic stroma which is typical for colorectal adenocarcinoma. TGF- $\beta 1$ also regulates integrin expression and acts as a motility factor (18). Thus, an increased expression and activation of TGF- 31 results in the formation of favorable tumor cell microenvironment promoting tumor migration. Also, the TGF- $\beta$ family is one of the most potent immunosuppressors described to date, since this mediator inhibits both cytotoxic lymphocytes and cytotoxicity of macrophages $(19,20)$.

All these effects are mediated by a number of different pathways. Best known among them is the Smad-family, activated via TGF- $\beta$-receptors on the cell surface. But TGF- $\beta$ can also activate the Erk, JNK and p38MAPK pathways (21). Activation of MAPK was shown in Smad-deficient cells (22) and even mutated TGF- 3 -receptor type I, defective in Smadactivation, mediated p38MAPK-activation by TGF-ß1 (23). This parallel activation of Smads and MAPKs is critical for proliferation, since Smads usually reduce, whereas JNK may 
Table I. Primers used.

Oligos for

Truncated TGF-ß1 target

Anti-TGF-ß1 ribozyme

Ribozyme expression

T7

BGH

Human TGF-ß1

Human aldolase
Sequences

Length of amplification

product (bp)

\section{5' TAATACGACTCACTATAGGACACGCAGTACAGCAAGGTC 3' 5' CGGGGCGGGGCGGGGCGGGGA 3'}

5' TAATACGACTCACTATAGGTCATGTTGCT

GATGAGTCCGTGAGGACGAAACAGCTGCTC 3'

5' TAATACGACTCACTATAGGG 3'

5' TAGAAGGCACAGTCGAGG 3'

5' GGCTGGAAGTGGATCCACGA 3'

5' GCAGGAGCGCACGATCATGTT 3'

5' ATCCTGGCTGCAGATGAGTC 3'

5' GCCCTTGTCTACCTTGATGC 3'
199

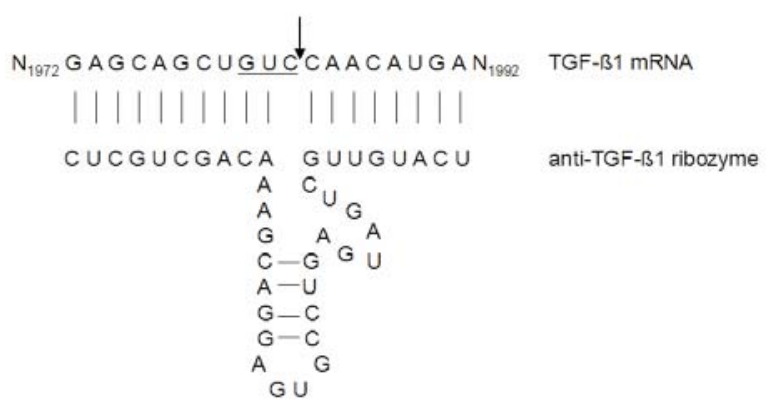

Figure 1. Sequence of the anti-TGF- 31 hammerhead ribozyme, shown in the prototypical hammerhead conformation, indicating base-pairing interactions between the ribozyme and the TGF-ß1-encoding target mRNA. Arrow indicates the predicted site of cleavage.

promote proliferation. Finally, there are also hints for activation of phosphatidylinositol-3-kinase (PI3K), resulting in Akt-phosphorylation (24), and for an interaction with protein phosphatase 2A (PP2A) (25).

TGF- $\beta 1$ has a variety of effects and its inhibition may fundamentally alter tumor cell proliferation, differentiation, microenvironment, invasion and host immune response. Therefore, we constructed a ribozyme to inhibit TGF- $\beta 1$ expression. We used HRT-18 colorectal adenocarcinoma cells, which produce and respond to TGF- 1 1, to investigate effects of diminished TGF- $\$ 1$ expression in respect to cell growth in vitro. Furthermore, we focused on cell adhesion and reactive oxygen intermediates (ROI) production of macrophages in co-culture with ribozyme-transfected HRT-18 cells. Finally, we investigated xenografts of native and ribozyme-transfected HRT-18 cells in nude mice.

\section{Materials and methods}

Cell culture. The human colorectal adenocarcinoma cell line HRT-18 was obtained from Cell Lines Service (Heidelberg,
Germany) and maintained in RPMI-1640 medium (Biochrom, Berlin, Germany) supplemented with $10 \%$ fetal calf serum (PAA, Cölbe, Germany). Monocyte isolation and cultivation as well as the co-culture model of MCTS (multicellular tumor spheroids) and macrophages were performed as described previously (20). The $25 \mathrm{~F} 9$ macrophage phenotype used in these experiments represents the mature fraction of human macrophages.

Design and synthesis of anti-TGF- $\beta 1$ hammerhead ribozyme Ribozyme-mediated RNA cleavage in vitro. To design an anti-TGF- $\beta 1$ ribozyme, a GTC site in exon 7 at nucleotide 1983 within the coding sequence for the mature peptide of the human TGF- 11 cDNA sequence (accession no. XO2812) was selected and tested according to Gibson and Shillitoe (26). The ribozyme and its respective target sequence are shown in Fig. 1.

Cleavage activity of this ribozyme was tested in a cellfree in vitro assay as described by Wichert et al (27). Oligo sequence for the anti-TGF- $\beta 1$ ribozyme and primer sequences for amplification of truncated TGF- $\beta 1$ target transcript out of total cDNA of TGF-ß1 expressing HRT-18 cells are shown in Table I.

Plasmid construction and stable transfection of HRT-18 cells. The ribozyme sequence was cloned into the eukaryotic expression vector pcDNA3.1/V5/HIS-TOPO (Invitrogen, Carlsbad, USA). Correct sequence and orientation of the insert were confirmed by sequencing. Circular pcDNA3.1 vector without ribozyme served as a negative control (mock). Transfections were performed using TransFast ${ }^{\mathrm{TM}}$ according to the manufacturer's instructions (Promega, Mannheim, Germany). Several stable cell clones resistant to G418 sulfate $(300 \mu \mathrm{g} / \mathrm{ml})$ were selected after 3 weeks and expanded for screening of ribozyme- and TGF- $\beta 1$ expression. Each of the clones was separately analyzed and one representative mock and ribozyme clone chosen for detailed characterization in comparison to non-transfected HRT-18 cells. 
Reverse transcription-polymerase chain reaction $(R T-P C R)$; real-time-PCR. Total RNA was isolated by the phenol/ isothiocyanate method using TRIzol-reagent (Gibco, Eggenstein, Germany). To compensate for variation in reverse transcription efficiency, cDNA from three independent reactions was pooled. Relative quantification of the TGF- 11 mRNA was performed by real-time PCR using the LightCycler FastStart DNA Master SYBR Green I kit (Roche, Mannheim, Germany) according to the manufacturer's instructions in the presence of $3 \mathrm{mM} \mathrm{MgCl}$ and the primers shown in Table I on a LightCycler ${ }^{\circledR}$ instrument (Roche). The housekeeping gene aldolase served as an external standard. The annealing temperatures were 55 and $58^{\circ} \mathrm{C}$ for $\mathrm{TGF}-\beta 1$ and aldolase, respectively. Standards for TGF- $\beta 1$ and aldolase were generated by cloning their PCR products in the pCR2.1 vector (Invitrogen). Plasmids were cultured in E. coli using standard procedures. The Maxi-Prep kit (Qiagen, Hilden, Germany) was used to isolate and purify the vector. A quantification curve was calculated facilitating serial dilutions of the standard vectors $\left(10^{8}-10^{3}\right.$ copies $)$ when amplified with the unknown samples within the same LightCycler run. Data calculations were performed by the second derivative maximum method. TGF- $\beta 1$ and aldolase copies were measured in three different runs and a ratio of TGF-ß1/aldolase copies was calculated. Only runs with an error $<0.05$ and an amplification efficiency $\geq 1.8$ were accepted. The mean ratio and standard deviation of three runs is shown.

TGF- $\beta 1$ enzyme-linked immunosorbent assay (ELISA). Supernatants of tumor cells were collected after $24 \mathrm{~h}$ of culture in serum-free medium, centrifuged and stored at $-80^{\circ} \mathrm{C}$. TGF- $\beta 1$ concentrations were measured using the human Quantikine $^{\text {TM }}$ TGF-ß1 immunoassay (R\&D Systems, Bad Nauheim, Germany).

Proliferation assay. Proliferation was assessed by counting the cells with a CASY cell counter (Schärfe Systems, Reutlingen, Germany). Cells were seeded in 6-well cluster plates and two wells of each clone were counted at days 2, 4, 6 and 9.

Adhesion assay. Microwell cluster plates (96) were coated with Matrige ${ }^{\circledR}$ Basement Membrane Matrix (Becton-Dickinson, Heidelberg, Germany) diluted in serum-free RPMI-1640 medium $(1 \mathrm{mg} / \mathrm{ml} ; 55 \mu \mathrm{l} /$ well $)$. Non-specific binding was blocked by incubating with $1 \%$ bovine serum albumin/PBS. Seven wells per group were plated with cells at a density of $3.5 \times 10^{4}$ cells $/ 100 \mu \mathrm{l} / \mathrm{well}$ and incubated for $90 \mathrm{~min}$ at $37^{\circ} \mathrm{C}$ with $5 \% \mathrm{CO}_{2}$ in a humidified incubator. Medium was aspirated, attached cells were fixed in $70 \%$ ethanol at $-20^{\circ} \mathrm{C}$ for $10 \mathrm{~min}$ and stained with crystal violet. After plates were rinsed with water, 0.2 Triton $\mathrm{X}-100 / 0.1 \mathrm{~N} \mathrm{HCl}$ was added to solubilize the cells and the absorbance of the solution was measured at $590 \mathrm{~nm}$.

Chemiluminescence assay. Production of ROI was measured on a Luminoskan RS luminometer (Labsystems, Helsinki, Finland) as described previously (20). Briefly, macrophages were cultured in 96-well plates in the presence of tumor cells (ratio 10:1) for $24 \mathrm{~h}$. ROI production was stimulated with $0.1 \mu \mathrm{M}$ PMA 15 min after adding $100 \mu \mathrm{M}$ Lucigenin to each well.

Xenografts in SCID-mice. Female BALB/c nude mice were purchased from Charles River Laboratories (Sulzfeld, Germany) and housed in an animal facility under specific pathogen-free conditions. All animal facilities and experiments were approved by local authorities. At the age of 6 weeks, $2.5 \times 10^{6}$ HRT-18 cells (native, ribozyme-transfected and mock clone, respectively) in $1 \times$ PBS solution were injected subcutaneously. In macrophage co-culture experiments, $2.5 \times 10^{5}$ cells of the $25 \mathrm{~F} 9$ macrophage phenotype were added. Xenograft growth was measured twice a week and tumor volumes were calculated. On day 30, mice were sacrificed and tumors isolated. One half of each tumor was frozen in liquid nitrogen immediately, whereas the other half was fixed in $4 \%$ neutral-buffered formalin solution for immunohistochemical studies. TGF- 31 mRNA expression was determined in a $5 \mathrm{~mm}$ cube of frozen tissue using realtime PCR as described previously.

Histological and immunohistochemical investigation of tumor tissue. Formalin-fixed tissue was processed using a routine wax-embedding procedure for histological examination, standard H\&E slides were stained, and two pathologists independently analyzed tumor differentiation and the degree of necrosis.

For immunohistochemical staining cell pellets of native, ribozyme-transfected and mock clone HRT-18 cells were embedded in wax using standard procedures. Slides $(2 \mu \mathrm{m})$ were deparaffinized using xylene and a series of alcoholwater solutions. Antigens were retrieved by incubation in citrate buffer ( $\mathrm{pH}$ 6.0) for $5 \mathrm{~min}$ in a steam cooker. Staining was performed using Dako ChemMate detection kit K5005 (Dako, Hamburg, Germany) following the instruction manual. The following antibodies were used: $\beta$-catenin (BD Transduction, Heidelberg, Germany, 1:5000), CEA (Novocastra/Leica Microsystems, Wetzlar, Germany, 1:100), E-cadherin (Dako, 1:50), MUC2 (Novocastra, 1:100), MUC4 (Zymed/Invitrogen, Karlsruhe, Germany, 1:100), MUC5AC (Novocastra, 1:50) and MUC6 (Novocastra, 1:50).

After haematoxylin counterstaining, slides were analyzed by two pathologists and the percentage of staining was determined.

Statistics. All data shown were obtained from at least three independent experiments and were expressed as mean $\pm \mathrm{SD}$ Statistical significance of in vitro experiments was determined by Student's t-test, for xenograft growth by ANOVA trend test, and for TGF- 11 expression as well as vital tumor masses in xenografts by Mann-Whitney U test. P-values $<0.05$ were considered to show a statistically significant difference.

\section{Results}

Ribozyme-mediated cleavage of truncated TGF- $\beta 1$ mRNA in a cell-free assay. The ability of the anti-TGF- $\beta 1$ ribozyme to cleave an in vitro transcribed truncated fragment of the TGF- 
Table II. TGF- $\$ 1$ expression in HRT-18 and transfected cells.

\begin{tabular}{|c|c|c|c|}
\hline & HRT-18 & Mock & Ribozyme \\
\hline \multicolumn{4}{|l|}{ TGF-ß1 mRNA } \\
\hline 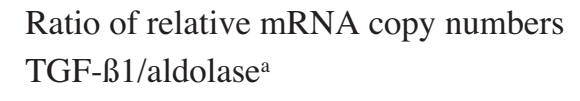 & $3.05 \pm 0.29$ & $8.72 \pm 0.6$ & $1.07 \pm 0.22$ \\
\hline \multicolumn{4}{|l|}{ TGF- $ß 1$ protein } \\
\hline TGF- $31 / 24 \mathrm{~h} / 10^{7}$ cells $^{\mathrm{b}}$ & $39 \mathrm{pg} / \mathrm{ml}$ & $78 \mathrm{pg} / \mathrm{ml}$ & $8 \mathrm{pg} / \mathrm{ml}$ \\
\hline
\end{tabular}

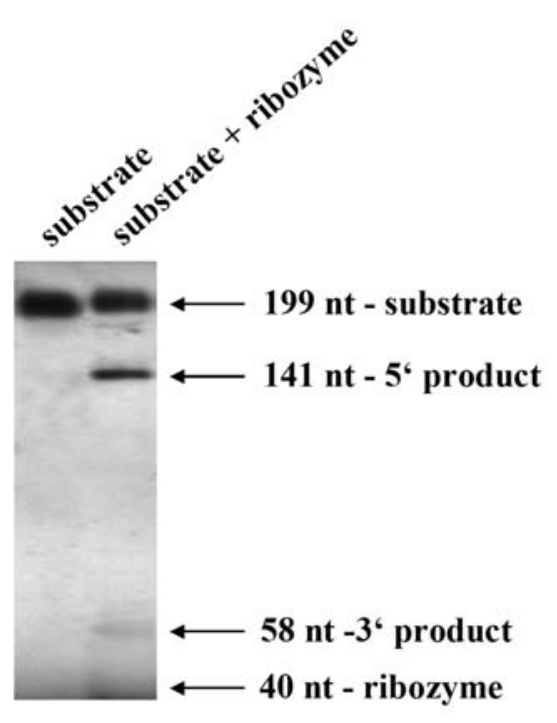

Figure 2. In vitro cleavage of a truncated TGF- 31 RNA substrate by the anti-TGF- 11 hammerhead ribozyme. Substrate $(150 \mathrm{nM})$ was incubated with $150 \mathrm{nM}$ ribozyme at $37^{\circ} \mathrm{C}$ for $90 \mathrm{~min}$ in the presence of $12 \mathrm{mM} \mathrm{MgCl}$. Samples were size-fractionated on an $8 \%$ polyacrylamide gel containing $7 \mathrm{M}$ urea. Cleavage products in the predicted size of 141 and $58 \mathrm{nt}$, and $199 \mathrm{nt}$ substrate were identified by autoradiography.
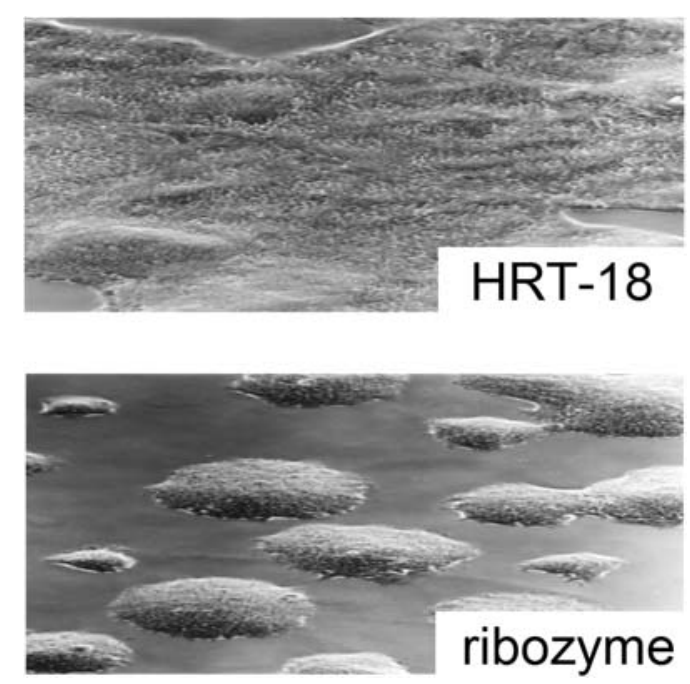

Figure 3. Growth pattern of native HRT-18 cells compared to ribozymetransfected cells. Macroscopic photos show a confluent layer of the native cell line, whereas ribozyme-transfected cells spread in clusters.
B1-encoding mRNA was shown in a cell-free system. The ribozyme degraded $\sim 40 \%$ of the truncated TGF- 31 -encoding mRNA fragment after $1.5 \mathrm{~h}$ at physiological $\mathrm{pH}$ and temperature, with equimolar concentrations of ribozyme and TGF-ß1 mRNA (Fig. 2).

Expression of anti-TGF- $\beta 1$ ribozyme and decreased expression of TGF- $\beta 1$ in HRT-18 cells. Clones expressing anti-TGF- $\beta 1$ ribozyme (30) and 6 mock-transfected clones of the human colorectal adenocarcinoma cell line HRT-18 were isolated and TGF- 11 expression was investigated. One representative clone of each group was selected for further detailed analysis.

Relative quantification of TGF- 31 mRNA in relation to the house-keeping gene aldolase by real-time PCR showed diminished TGF- $\beta 1$ mRNA levels in the ribozyme clone, but increased TGF- $\beta 1$ mRNA level in the mock clone compared to HRT-18 cells without transfection. In parallel, secreted TGF- $\beta 1$ protein was reduced $\sim 80 \%$ in the ribozyme clone measured by ELISA (Table II).

Inhibition of TGF- $\beta 1$ results in a different growth pattern, minor changes in protein expression, reduced cell adhesion on Matrigel, but has no effect on proliferation in vitro. While native HRT-18 and mock cells grow as confluent monolayer, the ribozyme-transfected cell clone forms slightly exalted clusters (Fig. 3).

Expression of a number of colorectal protein markers was slightly changed, ribozyme-transfected cells showed appearance of CEA (carcinoembryonic antigen), reduction of MUC5AC protein (mucin 5, subtypes A and C) and loss of MUC6 (mucin 6). All other proteins investigated showed no changes (Table III).

Adhesion was measured on Matrigel, a reconstituted basement membrane. HRT-18 cells adhered poorly to plastic surfaces of the culture well. The adhesion of the diminished TGF- 31 -expressing ribozyme clone on Matrigel was significantly reduced by $\sim 36 \%$, whereas the adhesion of the mock clone with higher TGF- $\beta 1$ expression increased $\sim 35 \%$ (Fig. 4).

Proliferation investigated by cell counting over a period of 9 days showed no significant varieties of proliferation between untransfected HRT-18 cells, ribozyme- and mocktransfected clone in the presence of $10 \%$ fetal calf serum (data not shown). 


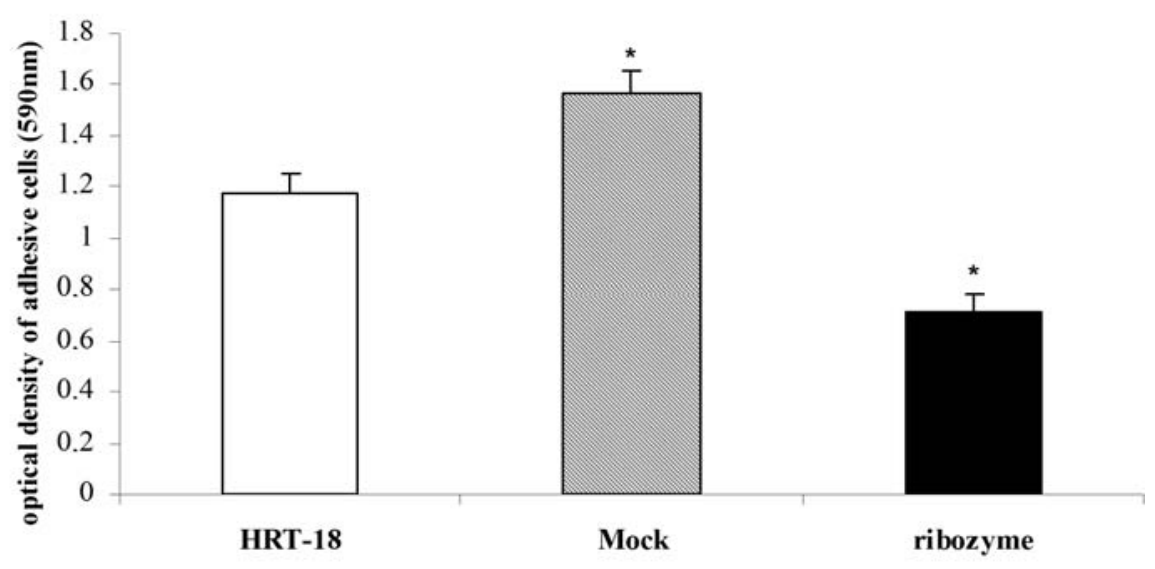

Figure 4. Cell adhesion of either HRT-18 cells, mock cells, HRT-18 clone transfected with vector, and ribozyme cells, HRT-18 clone transfected with the anti-TGF-ß1-ribozyme vector on Matrigel measured by crystal violet staining 90 min post-seeding. Adhesion of ribozyme-transfected cells was significantly decreased, whereas adhesion of mock-transfected cells was significantly increased compared to untransfected HRT-18 cells. Data of adhesive cells, mean \pm SD of three independent experiments are shown. ${ }^{*}$ Significant $(\mathrm{p}<0.05)$ in comparison to HRT-18 untransfected cells.

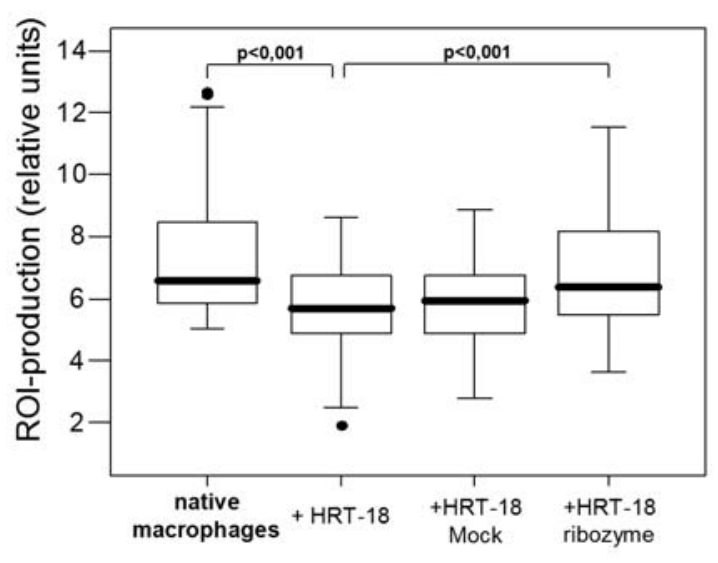

Figure 5. Production of ROI in tumor cell - macrophage co-cultures. Mature macrophage phenotype $25 \mathrm{~F} 9$ was co-cultured with multicellular tumor spheroids of either colorectal adenocarcinoma cells HRT-18, mock cells HRT-18 clone transfected with vector, and ribozyme cells - HRT-18 clone transfected with the anti-TGF-ß1-ribozyme vector. On day 4 of spheroid culture, macrophages were added for $24 \mathrm{~h}$. ROI were measured after stimulation with PMA by the lucigenin-amplified chemiluminescence method ROI production of macrophages was significantly inhibited by HRT-18 cells, but inhibition was abolished by expression of the anti-TGF- 1 ribozyme in the ribozyme-transfected clone.

Table III. Immunoreactive profile of native and ribozymetransfected HRT-18 cells.

\begin{tabular}{lcc}
\hline & HRT-18 native & HRT-18 ribozyme \\
ß-catenin & + & + \\
E-cadherin & + & + \\
CEA & - & partly + \\
MUC2 & - & - \\
MUC4 & - & - \\
MUC5AC & + & weakly + \\
MUC6 & + & - \\
\hline
\end{tabular}

Effect of the ribozyme expression in HRT-18 MCTS on the production of ROI in co-culture with the $25 F 9$ macrophage phenotype. Previously, we showed the inhibition of ROI production of different macrophage phenotypes by HRT-18 cells as well as an inhibition of ROI by recombinant TGF- 31 (20). Now, we measured ROI production of the mature macrophage phenotype $25 \mathrm{~F} 9$ in co-culture with MCTS of the ribozymetransfected HRT-18 clone and found that decreased expression of TGF- $\beta 1$ in HRT-18 cells causes abolishment of the inhibition of ROI production of $25 \mathrm{~F} 9$ macrophage phenotype as observed with untransfected HRT-18 cell spheroids and the mock clone (Fig. 5).

Xenografts of anti-TGF- $\beta 1$ ribozyme transfected tumor cells show reduced TGF- $\beta 1$ expression, but slightly enhanced tumor growth. Xenografts of either native HRT-18 or ribozyme-transfected HRT-18 cells were generated with and without the addition of human macrophages, respectively. Xenografts of ribozyme-transfected cells showed in both cases a slightly increased tumor growth. Due to the limited number of animals this increase did not reach statistical significance $(n=5, p=0.08$, respectively). The addition of macrophages retarded tumor growth in native and ribozymetransfected xenografts whereas the ribozyme-transfected ones were statistically significant $(\mathrm{p}=0.03)$ despite the comparatively low number of cases (Fig. 6).

TGF- $\beta 1$ levels in the xenograft tumors were quantified to assess the sustainability of the ribozyme induced TGF- $\$ 1$ suppression. As expected, xenografts consisting of ribozymetransfected cells contained reduced TGF- $\$ 1$ levels compared to those of native HRT-18 cells. Due to the limited number of samples, this difference did not reach statistical significance $(p=0.06)$. Xenografts of native or ribozymetransfected cells together with macrophages showed TGF- 1 expression levels between those extremes, whereas the contribution rate of the two cellular fractions was not determined (Fig. 7). 


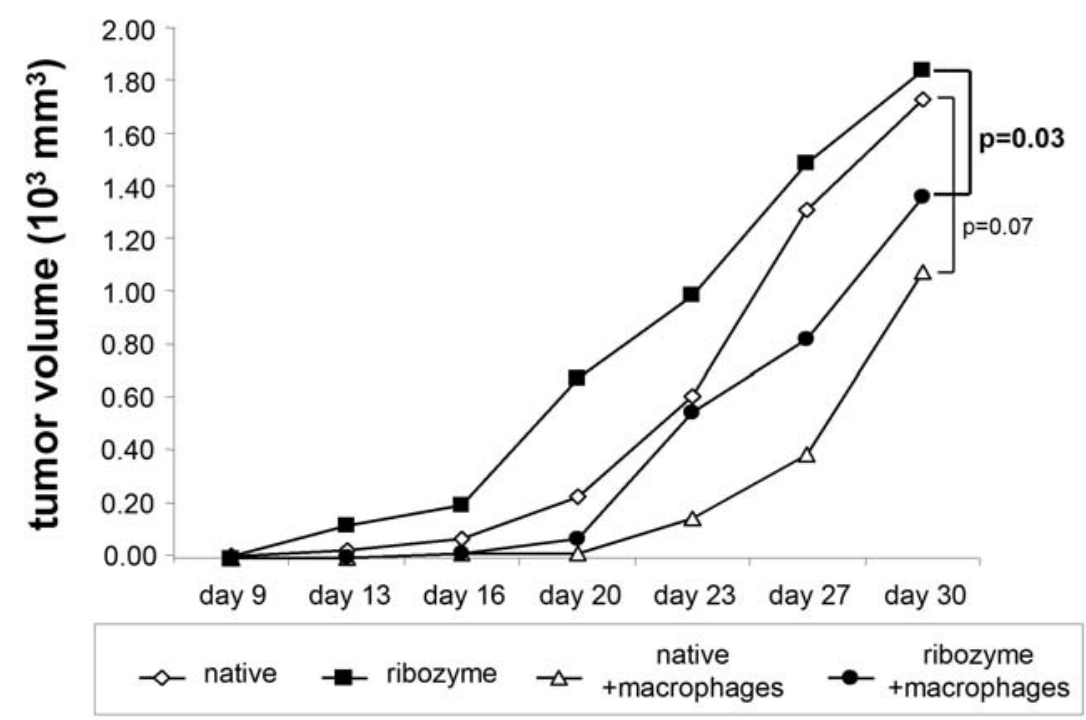

Figure 6. Growth of xenografts in nude mice. Native as well as ribozyme-transfected HRT-18 cells were injected in nude mice alone or together with human macrophages. Tumor volumes are calculated based on tumor diameters. In general, tumor sizes of ribozyme-transfected cells increased faster than those of native cells (not significant, $\mathrm{p}=0.08$, respectively). The addition of macrophages reduced tumor growth in native $(\mathrm{p}=0.07)$ as well as ribozyme-transfected cells $(\mathrm{p}=0.03)$.

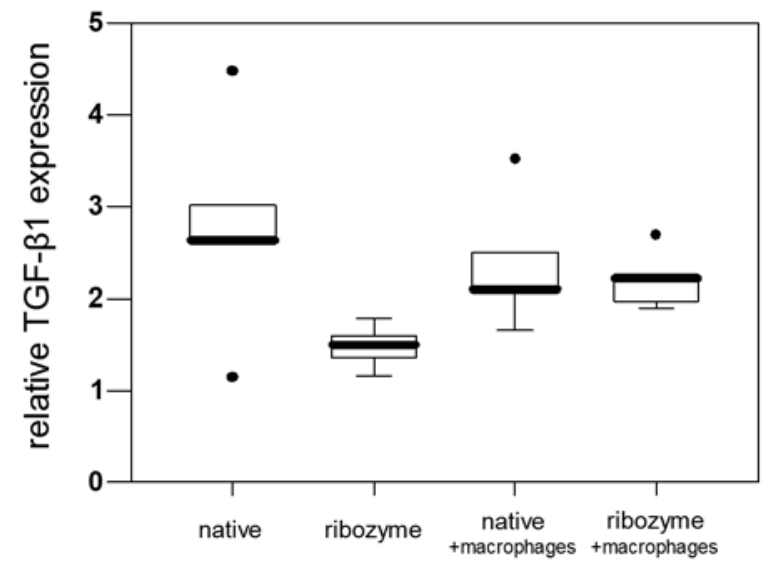

Figure 7. Relative TGF- $\beta 1$ expression in xenografts determined in a $5 \mathrm{~mm}$ cube of frozen tissue by real-time PCR. Ribozyme-transfected HRT-18 cells produced lower amounts of TGF- $\beta 1(\mathrm{p}=0.06)$. Addition of macrophages reduced TGF- 31 production of native HRT-18 cells slightly, but led to an increase in tumors of ribozyme-transfected cells $(\mathrm{p}=0.09)$.

Vital tumor masses of xenografts of anti-TGF- $\beta 1$ ribozymetransfected tumor cells were lighter than that of native $H R T$ 18 cells. To account for the different degrees of necrosis observed in the xenografts, vital tumor masses were calculated based on total masses and percentages of necrosis. Weight of ribozyme-transfected xenografts was reduced to one third compared to tumors of native HRT-18 $(n=5, p=0.09)$. This effect was slightly reduced when macrophages were added (Fig. 8).

\section{Discussion}

TGF- $\beta 1$ is produced by a number of malignancies and has been suggested to be a prognostic marker as well as a therapeutic target in patients with colorectal carcinoma (28).

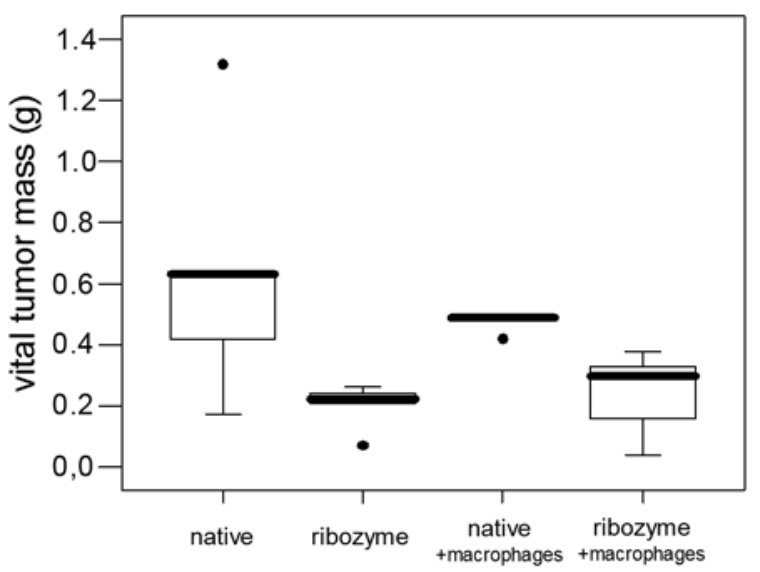

Figure 8. Final vital tumor masses of xenografts. Total masses of tumor tissue were measured after the sacrifice of mice. Vital tumor masses were calculated after histological determination of percentages of necrosis. Ribozyme-transfected HRT-18 cells showed lower vital tumor masses compared to native HRT-18 cells $(\mathrm{p}=0.09)$.

We constructed an anti-TGF- $\beta 1$ ribozyme and investigated its effects in stably transfected HRT-18 colorectal adenocarcinoma cells, which spontaneously produce this mediator. Additionally, we generated xenografts of these cells in nude mice, partly with addition of human macrophages.

Hammerhead ribozymes diminish gene expression by cleaving numerous copies of its respective mRNA-substrate (26). The herein described anti-TGF-B1 hammerhead ribozyme is directed against the human TGF- $\beta 1$ mRNA and does not cleave human TGF- $\$ 2$ or - 33 mRNA (data not shown). We were able to show that this ribozyme has endoribonucleolytic activity in a cell-free system. Stable transfection resulted in a significant inhibition of TGF-B1 expression on mRNA and protein level. Remarkably, TGF- $\beta 1$ expression was increased in all mock clones (which were transfected with the empty 
pcDNA3.1 vector) compared to untransfected HRT-18 control cells. We also found this vector effect in other cell lines (A27/80, OVCAR-3, 257P and 181P), which is in accordance with results from other authors (29).

Although secretion of TGF- $\beta 1$ was reduced by $80 \%$ in the ribozyme clone, this inhibition did not change proliferation of HRT-18 cells in vitro. In contrast, other studies described a growth-inhibiting effect of TGF- 11 in human colon carcinoma FET cells, mediated by TGF- $\beta 1$ antisense treatment (30). Similar, negative growth regulation by TGF-B1 was reported in a murine high-grade glioma model, in which TGF- $\beta$ inhibited tumor growth and enhanced apoptosis (31). These effects are not surprising as TGF- $\beta 1$ physiologically inhibits proliferation in normal epithelial cells. However, in transformed cells TGF- $\$ 1$ usually has no anti-proliferative effect or might act as growth stimulator (32). Effects of TGF-ß1 on proliferation are cell line-dependent and may even differ in various experimental settings. The determination whether TGF- $\beta 1$ has a positive or negative effect on proliferation is dependent on the current status of the TGF- $\beta 1$ signaling system as a whole. This comprises the amount of active TGF- $\beta 1$, expression of functional receptors and integrity of downstream signaling pathways $(21,33)$. The resulting effect of TGF- 31 seems to change during tumor progression in colon carcinoma (14) and was also investigated in a model of breast cancer progression (34). In the latter case, a switch was described within a single cell line at different stages of carcinogenesis. Furthermore, TGF- $\beta$ has tumor-suppressive effects on normal epithelium and low-grade invasive cancer, but acts pro-metastatically in high-grade invasive cancer.

It has also been discussed, that TGF- $\$ 1$ is an important factor in regulation of cell adhesion molecules and extracellular matrix production. It is thought to play a role in the composition of the tumor stroma and for modulation of tumor cell migration. In TGF- 31 antisense-transfected colon carcinoma FET cells $\alpha 5$-integrin was reduced which led to reduced adhesion of tumor cells to fibronectin (35). In our model, diminished TGF- 31 expression in HRT-18 ribozyme clone significantly decreased adhesion of tumor cells to Matrigel basement membrane matrix. Similar results are described in hepatocellular carcinoma cells in which TGF- 31 stimulated $\alpha 3$-integrin expression and triggered invasiveness (36).

In addition to these effects, it is known that TGF- $\beta 1$ acts as a very potent immunosuppressor. Together with other factors secreted by tumor cells, e.g. interleukin-10 or prostaglandin E2, it suppresses anti-tumor activity of immunocompetent cells which are no longer able to reject the tumor $(19,37)$. Especially, tumor-associated macrophages are converted to an anti-inflammatory behavior and promote tumor cells (38). A recent review summarized the immunosuppressive effects of TGF- $\beta 1$ on dendritic and effector $\mathrm{T}$ cells (39), whereas it had been shown that toxicity of cytotoxic $\mathrm{T}$ cells can be restored by TGF- $\beta$ depletion (40). On the basis of these observations, inhibition of TGF- 11 should attract inflammatory macrophages, restore cytotoxicity of $\mathrm{T}$ cells and hopefully switch the phenotype of tumor-associated macrophages back to an anti-tumor behavior. Support for this hypothesis comes from a study on the non-immunogenic rat prostate cancer line MATLyLu. After downregulation of TGF- $\beta 1$ by antisense strategy tumor incidence in normal rats was significantly decreased, whereas tumor incidence in immunodeficient rats was $100 \%$ (41).

Anti-tumoral cytotoxicity of macrophages is partly exerted by ROI (42), which can have anti-tumoral as well as tumor-promoting effects (43). We have previously shown that HRT-18 cells suppress the production of ROI by human macrophages in an in vivo-like co-culture model (20). Now we could demonstrate that this suppression is mediated in part by tumor-produced TGF-31. In our xenograft model, ribozyme-transfected tumors showed generally reduced vital tumor masses. This reduction was also seen in ribozymetransfected tumor cells in combination with human macrophages, although the experimental setting did not allow a clear differentiation between direct ribozyme-effects and overlapping effects of restored ROI production of tumorassociated macrophages. Nevertheless, inhibition of TGF- $\beta 1$ expression in tumor cells might maintain cytotoxic activities of tumor-associated macrophages in vivo.

Taken together, several effects of TGF- $\beta 1$ influence the behavior of tumors in vivo and result in different net effects. In our study, the constructed anti-TGF- $\$ 1$ ribozyme reduces cell adhesion and increases tumor necrosis in xenografts, with no significant changes in proliferation of the cell line HRT-18 used in this work. This positive correlation between TGF- $\beta 1$ and tumor progression is in accordance with other studies, i.e. in hepatocellular carcinoma (36), pulmonary adenocarcinoma (9), prostate (6) and colon cancer $(3,10$, $11,32,44)$.

Apart from immediate effects on tumor cells, inhibition of TGF-ß1 would also diminish immunosuppressive effects on macrophages and enhance their cytotoxic ROI production in the microenvironment of tumors. This reconstitution of the locally suppressed immune system might be an important factor for tumor elimination in addition to established tumor agents.

\section{Acknowledgements}

This work was supported by Deutsche Krebshilfe grant I0I523 and a generous donation of the family and friends of Mr. Jürgen Lühr, Wrestedt, Germany.

\section{References}

1. Higashi T, Sasagawa T, Inoue M, Oka R, Shuangying L and Saijoh K: Overexpression of latent transforming growth factorbeta 1 (TGF-beta 1) binding protein 1 (LTBP-1) in association with TGF-beta 1 in ovarian carcinoma. Jpn J Cancer Res 92: 506-515, 2001.

2. Saito H, Tsujitani S, Oka S, Kondo A, Ikeguchi M, Maeta M and Kaibara N: An elevated serum level of transforming growth factor-beta 1 (TGF-beta 1) significantly correlated with lymph node metastasis and poor prognosis in patients with gastric carcinoma. Anticancer Res 20: 4489-4493, 2000.

3. Tsushima H, Kawata S, Tamura S, et al: High levels of transforming growth factor beta 1 in patients with colorectal cancer: association with disease progression. Gastroenterology 110: 375-382, 1996.

4. Bedossa P, Peltier E, Terris B, Franco D and Poynard T: Transforming growth factor-beta 1 (TGF-beta 1) and TGF-beta 1 receptors in normal, cirrhotic, and neoplastic human livers. Hepatology 21: 760-766, 1995.

5. Christeli E, Zoumpourlis V, Kiaris H, Ergazaki M, Vassilaros S and Spandidos DA: TGF-ß1 overexpression in breast cancer: correlation with clinicopathological data. Oncol Rep 3: 11151118,1996 
6. Steiner MS and Barrack ER: Transforming growth factor-beta 1 overproduction in prostate cancer: effects on growth in vivo and in vitro. Mol Endocrinol 6: 15-25, 1992.

7. Krasagakis K, Tholke D, Farthmann B, Eberle J, Mansmann U and Orfanos CE: Elevated plasma levels of transforming growth factor (TGF)-beta1 and TGF-beta 2 in patients with disseminated malignant melanoma. Br J Cancer 77: 1492-1494, 1998.

8. Yamada N, Kato M, Yamashita H, Nister M, Miyazono K, Heldin $\mathrm{CH}$ and Funa $\mathrm{K}$ : Enhanced expression of transforming growth factor-beta and its type-I and type-II receptors in human glioblastoma. Int J Cancer 62: 386-392, 1995.

9. Takanami I, Imamura T, Hashizume T, Kikuchi K, Yamamoto Y and Kodaira S: Transforming growth factor beta 1 as a prognostic factor in pulmonary adenocarcinoma. J Clin Pathol 47: 1098-1100, 1994.

10. Tsushima H, Ito N, Tamura S, et al: Circulating transforming growth factor beta 1 as a predictor of liver metastasis after resection in colorectal cancer. Clin Cancer Res 7: 1258-1262, 2001 .

11. Friedman E, Gold LI, Klimstra D, Zeng ZS, Winawer S and Cohen A: High levels of transforming growth factor beta 1 correlate with disease progression in human colon cancer Cancer Epidemiol Biomarkers Prev 4: 549-554, 1995.

12. Langerak AD and Garewal HS: Transforming growth factorbeta 1: a useful tumor marker in patients with colorecta carcinoma? Cancer 85: 517-519, 1999.

13. Pardali K and Moustakas A: Actions of TGF-beta as tumor suppressor and pro-metastatic factor in human cancer. Biochim Biophys Acta 1775: 21-62, 2007.

14. Hsu S, Huang F, Hafez M, Winawer S and Friedman E: Colon carcinoma cells switch their response to transforming growth factor beta 1 with tumor progression. Cell Growth Differ 5: 267-275, 1994.

15. Grady WM, Myeroff LL, Swinler SE, et al: Mutational inactivation of transforming growth factor beta receptor type II in microsatellite stable colon cancers. Cancer Res 59: 320-324, 1999.

16. Matsuzaki K, Seki T and Okazaki K: TGF-beta during human colorectal carcinogenesis: the shift from epithelial to mesenchymal signaling. Inflammopharmacology 14: 198-203, 2006.

17. Hauptmann S, Siegert A, Berger S, et al: Regulation of cell growth and the expression of extracellular matrix proteins in colorectal adenocarcinoma: a fibroblast-tumor cell coculture model to study tumor-host interactions in vitro. Eur J Cell Biol 82: 1-8, 2003.

18. Hagedorn HG, Bachmeier BE and Nerlich AG: Synthesis and degradation of basement membranes and extracellular matrix and their regulation by TGF-beta in invasive carcinomas (Review). Int J Oncol 18: 669-681, 2001.

19. De Visser KE and Kast WM: Effects of TGF-beta on the immune system: implications for cancer immunotherapy. Leukemia 13: 1188-1199, 1999.

20. Siegert A, Denkert C, Leclere A and Hauptmann S: Suppression of the reactive oxygen intermediates production of human macrophages by colorectal adenocarcinoma cell lines. Immunology 98: 551-556, 1999.

21. Derynck R and Zhang YE: Smad-dependent and Smadindependent pathways in TGF-beta family signalling. Nature 425: 577-584, 2003.

22. Engel ME, McDonnell MA, Law BK and Moses HL: Interdependent SMAD and JNK signaling in transforming growth factor-beta-mediated transcription. J Biol Chem 274: 37413-37420, 1999.

23. Yu L, Hebert MC and Zhang YE: TGF-beta receptor-activated p38 MAP kinase mediates Smad-independent TGF-beta responses. EMBO J 21: 3749-3759, 2002.

24. Bakin AV, Tomlinson AK, Bhowmick NA, Moses HL and Arteaga CL: Phosphatidylinositol 3-kinase function is required for transforming growth factor beta-mediated epithelial to mesenchymal transition and cell migration. J Biol Chem 275: 36803-36810, 2000.

25. Griswold-Prenner I, Kamibayashi C, Maruoka EM, Mumby MC and Derynck R: Physical and functional interactions between type I transforming growth factor beta receptors and Balpha, a WD-40 repeat subunit of phosphatase 2A. Mol Cell Biol 18: 6595-6604, 1998.
26. Gibson SA and Shillitoe EJ: Ribozymes. Their functions and strategies for their use. Mol Biotechnol 7: 125-137, 1997.

27. Wichert A, Holm PS, Dietel M and Lage H: Selection of a high activity ribozyme against cytostatic drug resistance-associated glypican-3 using an in vitro assay containing total tumor RNA. Cancer Gene Ther 6: 263-270, 1999.

28. Anzano MA, Rieman D, Prichett W, Bowen-Pope DF and Greig R: Growth factor production by human colon carcinoma cell lines. Cancer Res 49: 2898-2904, 1989.

29. Lohr M, Schmidt C, Ringel J, Kluth M, Muller P, Nizze H and Jesnowski R: Transforming growth factor-beta 1 induces desmoplasia in an experimental model of human pancreatic carcinoma. Cancer Res 61: 550-555, 2001.

30. Wu SP, Theodorescu D, Kerbel RS, Willson JK, Mulder KM, Humphrey LE and Brattain MG: TGF-beta 1 is an autocrinenegative growth regulator of human colon carcinoma FET cells in vivo as revealed by transfection of an antisense expression vector. J Cell Biol 116: 187-196, 1992.

31. Ashley DM, Kong FM, Bigner DD and Hale LP: Endogenous expression of transforming growth factor betal inhibits growth and tumorigenicity and enhances Fas-mediated apoptosis in a murine high-grade glioma model. Cancer Res 58: 302-309, 1998.

32. Huang F, Newman E, Theodorescu D, Kerbel RS and Friedman E: Transforming growth factor beta 1 (TGF beta 1) is an autocrine positive regulator of colon carcinoma U9 cells in vivo as shown by transfection of a TGF beta 1 antisense expression plasmid. Cell Growth Differ 6: 1635-1642, 1995.

33. Ye SC, Foster JM, Li W, et al: Contextual effects of transforming growth factor beta on the tumorigenicity of human colon carcinoma cells. Cancer Res 59: 4725-4731, 1999.

34. Tang B, Vu M, Booker T, Santner SJ, Miller FR, Anver MR and Wakefield LM: TGF-beta switches from tumor suppressor to prometastatic factor in a model of breast cancer progression. $\mathrm{J}$ Clin Invest 112: 1116-1124, 2003.

35. Wang D, Zhou GH, Birkenmeier TM, Gong J, Sun L and Brattain MG: Autocrine transforming growth factor beta 1 modulates the expression of integrin alpha 5 beta 1 in human colon carcinoma FET cells. J Biol Chem 270: 14154-14159, 1995.

36. Giannelli G, Fransvea E, Marinosci F, Bergamini C, Colucci S, Schiraldi $\mathrm{O}$ and Antonaci $\mathrm{S}$ : Transforming growth factor-beta1 triggers hepatocellular carcinoma invasiveness via alpha3beta1 integrin. Am J Pathol 161: 183-193, 2002.

37. Wojtowicz-Praga S: Reversal of tumor-induced immunosuppression by TGF-beta inhibitors. Invest New Drugs 21: 2132, 2003.

38. Lewis CE and Pollard JW: Distinct role of macrophages in different tumor microenvironments. Cancer Res 66: 605-12, 2006.

39. Rabinovich GA, Gabrilovich D and Sotomayor EM: Immunosuppressive strategies that are mediated by tumor cells. Annu Rev Immunol 25: 267-296, 2007.

40. Thomas DA and Massague J: TGF-beta directly targets cytotoxic $\mathrm{T}$ cell functions during tumor evasion of immune surveillance. Cancer Cell 8: 369-380, 2005.

41. Matthews E, Yang T, Janulis L, Goodwin S, Kundu SD, Karpus WJ and Lee C: Down-regulation of TGF-beta1 production restores immunogenicity in prostate cancer cells. Br J Cancer 83: 519-525, 2000.

42. Adams DO and Hamilton DA: Macrophages as destructive cells in host defense. In: Inflammation: Basic Principles and Clinical Correlates. Galin JI, Goldstein IM and Syndermann R (eds). Raven Press, New York, pp637-662, 1992.

43. Wu WS: The signaling mechanism of ROS in tumor progression. Cancer Metastasis Rev 25: 695-705, 2006.

44. Narai S, Watanabe M, Hasegawa H, Nishibori H, Endo T, Kubota T and Kitajima M: Significance of transforming growth factor beta 1 as a new tumor marker for colorectal cancer. Int $\mathbf{J}$ Cancer 97: 508-511, 2002. 